\title{
RESPUESTA HIDROLÓGICA AL EVENTO DE PRECIPITACIÓN DE JUNIO DE 2013 EN EL PIRINEO CENTRAL
}

\author{
Roberto Serrano Notivoli ${ }^{1,2}$, Daniel Mora Mur ${ }^{1,2,3}$, Alfredo Ollero Ojeda ${ }^{1,2}$, \\ Miguel Sánchez Fabre ${ }^{1,2}$ y Miguel Ángel Saz Sánchez ${ }^{1,2}$ \\ ${ }^{1}$ Departamento de Geografía y Ordenación del Territorio. Universidad de Zaragoza \\ ${ }^{2}$ Instituto Universitario de Ciencias Ambientales. Universidad de Zaragoza \\ ${ }^{3}$ Mastergeo. Medio Ambiente, Territorio y Geografía S.L.
}

\section{RESUMEN}

El presente trabajo analiza la respuesta hidrológica de la cabecera del Cinca, cuenca del Ésera y cabecera del Esca al episodio de precipitación intensa que se produjo en el Pirineo central durante los días 17 a 19 de junio de 2013. Se utilizan 122 observatorios meteorológicos para estudiar el comportamiento de la precipitación a diferentes escalas temporales, y 7 estaciones de aforo para observar la temporalidad y la intensidad de la respuesta de los caudales. La intensidad de la descarga de lluvia, sin ser extraordinaria en la serie histórica, se sumó a la fusión de un almacenamiento de nieve todavía presente en la cabecera de las cuencas, lo que produjo un incremento de caudal de magnitud destacada en los tramos altos de las cuencas. Las consecuencias de las avenidas han reactivado procesos geomorfológicos fluviales, reocupando antiguos llanos de inundación, aunque la intensa ocupación territorial de los últimos 50 años en el Valle de Benasque ha producido que la exposición al riesgo sea mucho mayor como consecuencia del escasamente controlado y desordenado crecimiento urbanístico.

Palabras clave: Pirineo, crecida hidrológica, Cinca, Ésera, Esca, Benasque, Aragón.

\section{ABSTRACT}

\section{Hydrological response to precipitation event on june 2013 in central Pyrenees.}

In this paper is analyzed the hydrological response of Cinca and Esca headwaters, and Ésera basin to a intense precipitation episode, produced in central Pyrenees from $17^{\text {th }}$ to $19^{\text {th }}$ june 2013.122 meteorological stations are used to study rainfall behavior in different temporal scales, and 7 gauges to view temporality and intensity on flow responses. Rainfall discharge was not unusual in historical series, but it joined to a snowmelt, which produced an increase on flow at highest headwaters. The consequences of floods have reactivated fluvial geomorphic processes, reoccupying former floodplain, although the intense territorial occupation of the last 50 years in the Valley of Benasque has produced that exposure to risk is much higher as a result of poorly controlled urban growth.

Keywords: Pyrenees, hydrological flood, Cinca, Ésera, Esca, Benasque, Aragón

\section{INTRODUCCIÓN}

Los eventos de precipitación extremos en el Pirineo pueden provocar incrementos de caudal que, asociados a la actividad geomorfológica en el entorno y en función de la intensidad y duración de la precipitación registrada, provocan riesgo en el normal desarrollo de la actividad antrópica. La probabilidad de ocurrencia de fenómenos extremos de precipitación en los Pirineos ha sido estudiada ampliamente (García-Ruiz et al, 1998; Beguería y Lorente, 1999; García-Ruiz et al, 2000a; García-Ruiz et al, 2000b; Lopez Moreno et al., 2006; Vicente-Serrano et al, 2007, Trapero et al, 2013; Serrano-Muela et al, 2013), así como la caracterización de la convección (Álvarez et al., 2011), un fenómeno muy frecuente en el área pirenaica, que provoca la mayor parte de las tormentas anuales en esta zona. Estas precipitaciones intensas generan, con frecuencia, crecidas violentas (Plana, 1984; García Ruiz et al., 2000; Rico et al., 2001). Estos procesos han sido también estudiados en la vertiente francesa (Staron, 1993; Antoine et al., 2001).

Contacto: Roberto Serrano Notivoli: rs@unizar.es; Daniel Mora Mur: dmoramur@gmail.com; Alfredo Ollero Ojeda: aollero@unizar.es; Miguel Sánchez Fabre: msanchez@unizar.es; Miguel Ángel Saz Sánchez: masaz@unizar.es 
A pesar de la tendencia habitual en agregados mensuales o estacionales de la precipitación, la altitud influye escasamente en eventos excepcionales (más de $200 \mathrm{~mm}$ en 24 horas), y es relativamente importante para los de alta intensidad (150-200mm) (García-Ruiz et al, 1998).

El registro histórico de precipitaciones muestra de una manera más o menos habitual eventos extremos de intensidad extraordinaria en relación al conjunto de la serie. Es claro el ejemplo del evento de principios de agosto de 1963 en los valles del Ésera y Noguera-Ribagorzana especialmente, donde se registraron $145 \mathrm{~mm}$ en dos días en Benasque, o el evento de noviembre de 1982, cuando se registraron $195 \mathrm{~mm}$ en Torla, $218 \mathrm{~mm}$ en Fiscal, y $400 \mathrm{~mm}$ en el fondo de valle del Cinqueta. En el refugio de Góriz (2265 m.s.n.m.) ese día se registraron más de $600 \mathrm{~mm}$ en 24 horas, aunque no se puede establecer una cifra concreta por desbordamiento del pluviómetro (García-Ruiz et al, 2000a). En agosto de 1996 la avenida sobre el barranco de Arás provocó la muerte de 87 personas como consecuencia de la descarga ingente de sedimento de la cuenca a partir de una lluvia estimada de más de $200 \mathrm{~mm}$ en una hora (GarcíaRuiz et al, 1998). Pero estos grandes eventos no son los únicos, en mayo de 1999 se registraron en el valle de Aísa $70 \mathrm{~mm}$ en 10 minutos, confirmando que las lluvias más extremas presentan una distribución errática (García-Ruiz et al, 2000a).

El 18 de junio de 2013 se produjo un evento de precipitación extrema en la cabecera del Ésera que se extendió hacia el Oeste durante 48 horas hasta concentrarse de nuevo en la zona occidental del macizo pirenaico. Los impactos producidos sobre áreas urbanizadas fueron considerables en la cuenca del Ésera. El presente trabajo se estructura en: 1) un análisis de la situación meteorológica que dio lugar al evento; 2) la respuesta hidrológica de los caudales directamente afectados y los impactos producidos sobre el medio humano y geomorfológico; 3) búsqueda de convergencias con otros eventos de similares características en el macizo pirenaico; 4) análisis global de los impactos.

\section{2. ÁREA DE ESTUDIO}

Los eventos de intensa precipitación y crecidas fluviales de junio de 2013 afectaron a todo el Pirineo central en ambas vertientes. Para el presente artículo se han considerado las cabeceras de los ríos Cinca (incluyendo toda la cuenca del Ésera) y Esca (Fig. 1), teniendo en cuenta los valores pluviométricos e hidrológicos en ella alcanzados y los daños registrados.

Figura 1. Localización del área de estudio.

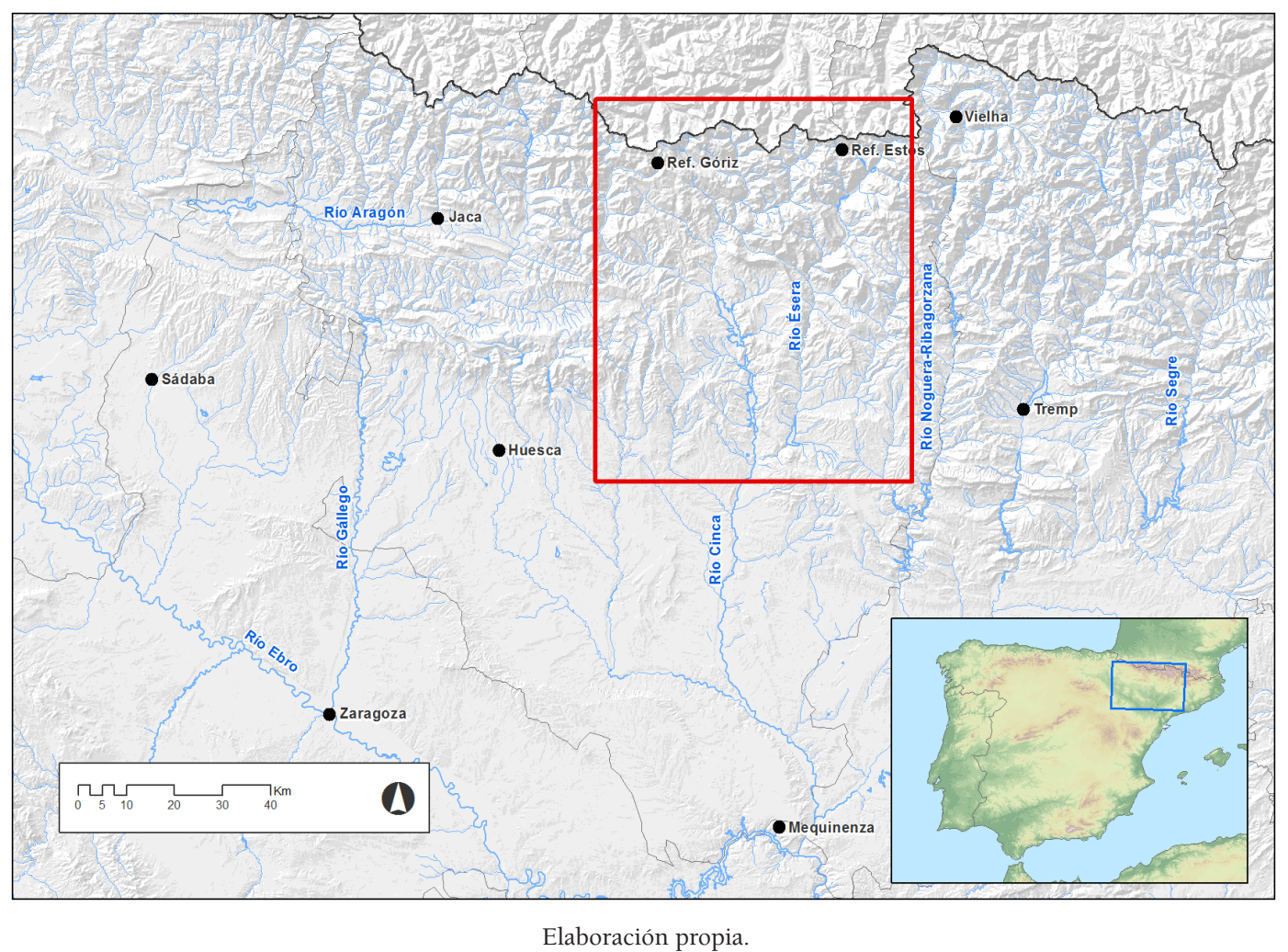


Los Pirineos son una barrera montañosa de $435 \mathrm{~km}$. de longitud con una complejidad orográfica que favorece el desarrollo de tormentas convectivas, aumentando el efecto de los sistemas frontales (Beguería y Lorente, 1999) provenientes principalmente de la orla mediterránea. En la zona occidental del macizo, Beguería y Lorente (1999) señalan que la frecuencia de eventos extremos es elevada especialmente en el alto Pirineo y al Sur de las Sierras Interiores, sin embargo, en las sierras del flysh y Depresión media, con la misma frecuencia la intensidad de los eventos es menor.

Afluente del Cinca, el río Ésera drena una cuenca de $1.531 \mathrm{~km}^{2}$ en la que se ubican las máximas alturas de la cordillera pirenaica. De muy activa geomorfología, destacan el modelado glaciar con gran desarrollo de depósitos morrénicos (Serrano y Martínez de Pisón, 1994), fenómenos kársticos, canales de aludes en la zona granítica de cabecera, canchales de pie de vertiente, conos de deyección, deslizamientos en materiales pizarrosos, etc. (Cadiñanos et al., 2001). El trazado del Ésera sigue a grandes rasgos una disposición estructural. Apenas quedan retazos de depósitos fluviales antiguos, desmantelados por la acción glaciar. El cauce del Ésera presenta modelo anastomosado en los rellanos glaciares superiores, sectores encajados con saltos y cascadas al atravesar los granitos y algunos tramos trenzados aguas abajo de Benasque muy alterados por las obras de defensa y extracciones de áridos (Del Valle et al., 2007). Desde El Rún el Ésera se enfrenta a una sucesión de congostos (Ventamillo, Argoné, Santaliestra) con lecho rocoso y de tramos amplios de valle en los que desarrolla modelos recto-meandriformes y meandriformes de baja sinuosidad (González Amuchastegui et al., 1998)

\section{MATERIAL Y MÉTODOS}

Los datos con los que se realizan los hidrogramas y el análisis de este evento de crecida se han obtenido del SAIH (Sistema Automático de Información Hidrológica) de la Confederación Hidrográfica del Ebro (CHE). También se ha recurrido al Anuario de Aforos del Ministerio de Agricultura, Alimentación y Medio Ambiente. Del río Cinca se ha seleccionado una estación de aforo del tramo alto (Escalona) y otra del bajo Cinca (Fraga) para apreciar el desigual alcance de la crecida en ambos ámbitos de la cuenca. Del Ésera, dada la importancia que el episodio de crecida ha tenido en su cuenca, se han utilizado los datos de los tres aforos repartidos por su cauce (Eriste, Campo, Graus). Finalmente, también se han usado las dos estaciones de aforo existentes en el río Esca, una en su tramo alto (Isaba) y otra próxima a su desembocadura en el río Aragón, a través del embalse de Yesa (Sigües) (Fig. 2).

Figura 2. Localización de las estaciones de aforo (azul) y los observatorios meteorológicos de su entorno (amarillo).

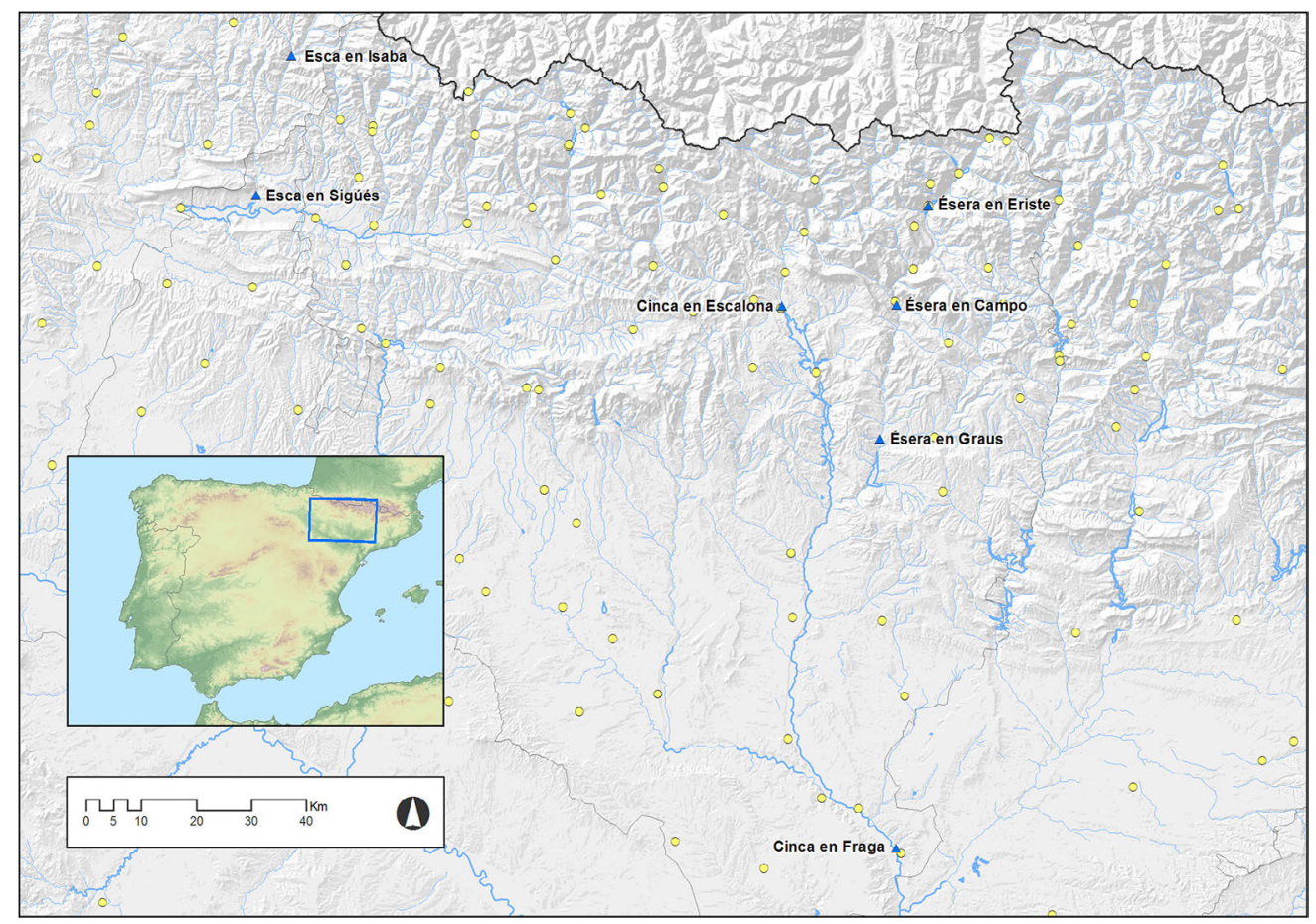

Elaboración propia. 
Para matizar la distribución espacio-temporal de la precipitación, se utilizaron datos a escala horaria para los días 18 y 19 de junio de 2013 de 122 observatorios automáticos, 33 de los cuales pertenecen a la red de AEMET, y 89 a la CHE. Los agregados diarios se extrajeron de un total de 204 estaciones automáticas y manuales, perteneciendo 91 de ellas a AEMET, 81 a la CHE, y 32 a la Oficina del Regante del Gobierno de Aragón (Fig. 2). El 98\% de los observatorios utilizados para el presente trabajo se sitúan por debajo de los 2000 m.s.n.m., y muestran una gradación de incremento en altura de las precipitaciones medias y la inversa en temperaturas. Asimismo el gradiente longitudinal es de mayor humedad en el Oeste con la influencia Atlántica que va disminuyendo hacia la orla Mediterránea, justo a la inversa de las temperaturas, que aumentan de manera longitudinal (Cuadrat et al, 2012; García-Ruiz et al, 2000b).

Los mapas sinópticos y las imágenes de satélite utilizadas para el análisis meteorológico se han obtenido de la Agencia Estatal de Meteorología.

\section{GÉNESIS ATMOSFÉRICA Y VALORES REGISTRADOS}

La situación sinóptica que dio lugar a las crecidas fluviales en la cuenca del Ésera y zona oriental de Aragón y Pirineo leridano, se configura el día 17 de junio de 2013 por el descenso desde latitudes superiores de una bolsa de aire frío en altura. Esta bolsa fría con reflejo de una baja presión de unos $1010 \mathrm{mb}$, se desplaza desde el SW de Irlanda hasta la vertical de Portugal, con una trayectoria muy marcada de Norte a Sur (NNW-SSW).

Durante el día 17 y 18 de junio ese embolsamiento frío permanece al W de la Península avanzando lentamente hacia el este. El mapa del día 18 (Fig. 3) muestra la situación a nivel sinóptico reflejando la presencia de una bolsa fría a nivel de $500 \mathrm{hpa}$. prácticamente asilada de la corriente en chorro, es decir, se produce la formación de una Depresión Aislada en Niveles Altos (DANA) en la zona centro-oeste de la Península.

Figura 3. Mapa sinóptico en altura $(500 \mathrm{hPa})$ de presión y temperatura del 18 de junio a las $18 \mathrm{UTC}$.

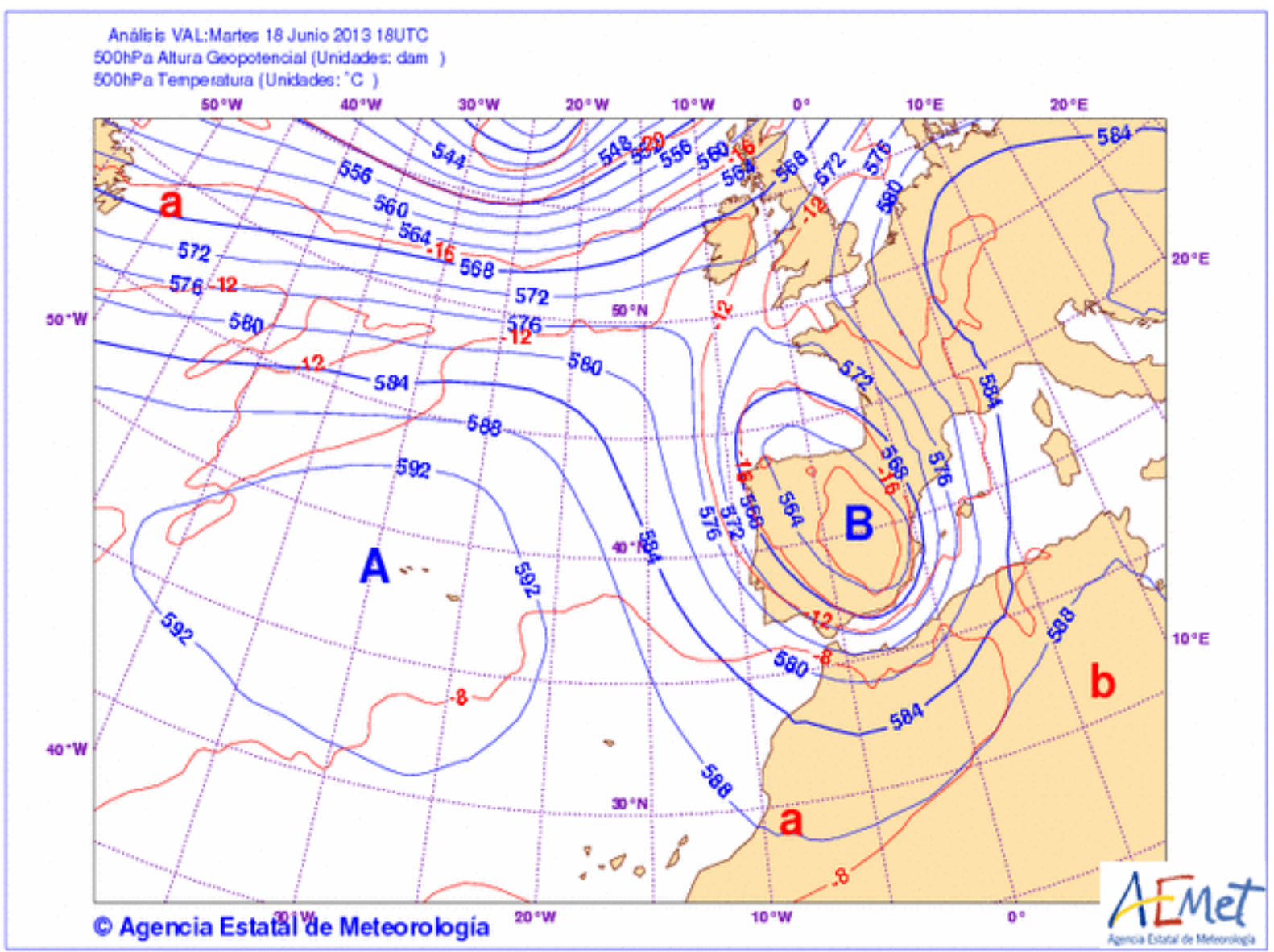

Fuente: AEMET. 
Esta bolsa fría tiene en su centro una temperatura de unos $-22 /-23^{\circ} \mathrm{C}$ a la altura de $500 \mathrm{hpa}$ y abarca una superficie muy amplia. A 850 hpa se establece un marcado gradiente térmico entre el reflejo del centro de la DANA, con temperaturas de $3-4^{\circ} \mathrm{C}$ y la parte delantera de la misma, en la zona este de la Península. Por ejemplo, en el Pirineo aragonés, a ese mismo nivel, se preveían temperaturas cercanas a los $20^{\circ} \mathrm{C}$.

El pequeño reflejo en superficie que tiene esa DANA es suficiente para que se genere un flujo de vientos de levante y SE provenientes del mar Mediterráneo, lo que aporta una humedad extra a la situación, favoreciendo el desarrollo de sistemas convectivos que, fruto de lento avance de la bolsa fría, se convierten en sistemas muy estáticos.

Figura 4. Imagen de masas de aire de las 16:00h del día 17 de junio. Radar de esa misma hora.
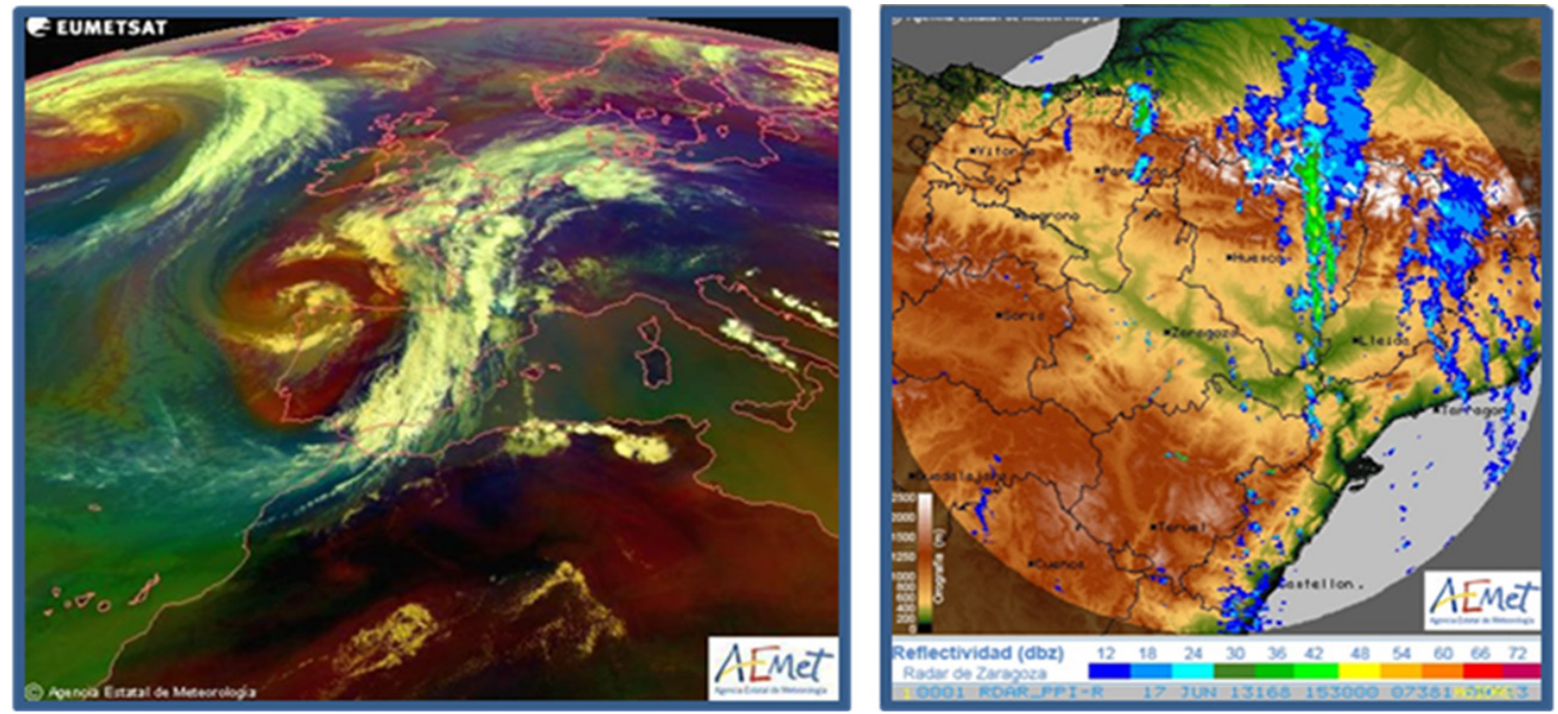

Fuente: AEMET.

La imagen de satélite de masas de aire de las 16:00h del día 17 de junio de 2013 (Fig. 4) muestra la bolsa fría con centro sobre Galicia, ya muy descolgada de su tránsito habitual por latitudes más altas. Esta bolsa fría tiene nubosidad asociada en la parte delantera, la más inestable, con activas estructuras tormentosas embebidas. La imagen del radar en torno a las 17:30h, muestra una estructura tormentosa muy activa en forma de línea de turbonada, afectando al sector NE de la provincia de Huesca. Los pluviómetros de la Confederación Hidrográfica del Ebro (CHE) registran eventos puntuales de precipitación puntuales de más de $12 \mathrm{~mm} / \mathrm{h}$ de intensidad.

En el transcurso del día 18 la situación se muestra prácticamente estacionaria, con una activa estructura nubosa incidiendo de Sur a Norte sobre el Pirineo oriental aragonés y zonas vecinas como el valle de Arán. Al ya de por si importante dinamismo de la situación, hay que unir el efecto de disparo orográfico que los Pirineos ejercieron sobre las precipitaciones. Las cantidades de lluvia son tanto más cuantiosas cuanto mayor es la altitud.

El evento de tormentas se da dentro de los límites espaciales y temporales habituales de la convección, siendo en el mes de junio más frecuentes en la orla oriental del Pirineo Aragonés, y entre las 12 y las 21 horas (Álvarez et al., 2011). Durante el día 18 se produjeron las mayores precipitaciones, aunque la descarga que continuó el día 19 contribuyó a saturar todavía más el suelo con sus consecuencias hidrológicas y geomorfológicas. Los valores acumulados en dos días registran más de $150 \mathrm{~mm}$ en la cabecera del Ésera y el Cinca, disminuyendo hacia el sur, siendo el patrón longitudinal menos claro.

La distribución espacio-temporal horaria de la lluvia del día 18 (Fig. 5) muestra una rápida acumulación especialmente en la orla occidental de la provincia de Lérida (Segre-Isóvol: $93.8 \mathrm{~mm} / 24 \mathrm{~h}$ ), que se va desplazando hacia el Oeste, obteniendo valores muy altos de acopio de lluvia en el margen occidental del Pirineo aragonés, especialmente en las localidades de Hecho $(85 \mathrm{~mm} / 24 \mathrm{~h})$ y Jaca $(85.8 \mathrm{~mm} / 24 \mathrm{~h})$.

Tras el veloz desarrollo de la situación durante el día 18, los observatorios pirenaicos continuaron registrando precipitación durante las 24 horas posteriores. Seis de ellos acumularon en los dos días más de 100 litros, siendo los más destacados el refugio de La Renclusa (2.140 m.s.n.m) con 256 mm, Belagua (1.382 m.s.n.m) con 157.8 mm, y el refugio de Estós (1.890 m.s.n.m) con 155 mm (Tabla 1). 
Figura 5. Acumulación horaria del día 18. En fondo verde, azul, y amarillo las provincias de Navarra, Huesca, y Lérida respectivamente. Precipitación acumulada en blanco (más de $1 \mathrm{~mm} / \mathrm{h}$ ), amarillo (más de $10 \mathrm{~mm} / \mathrm{h}$ ), rosa (más de $25 \mathrm{~mm} / \mathrm{h}$ ), azul (más de $50 \mathrm{~mm} / \mathrm{h}$ ), y negro (más de $80 \mathrm{~mm} / \mathrm{h}$ ).

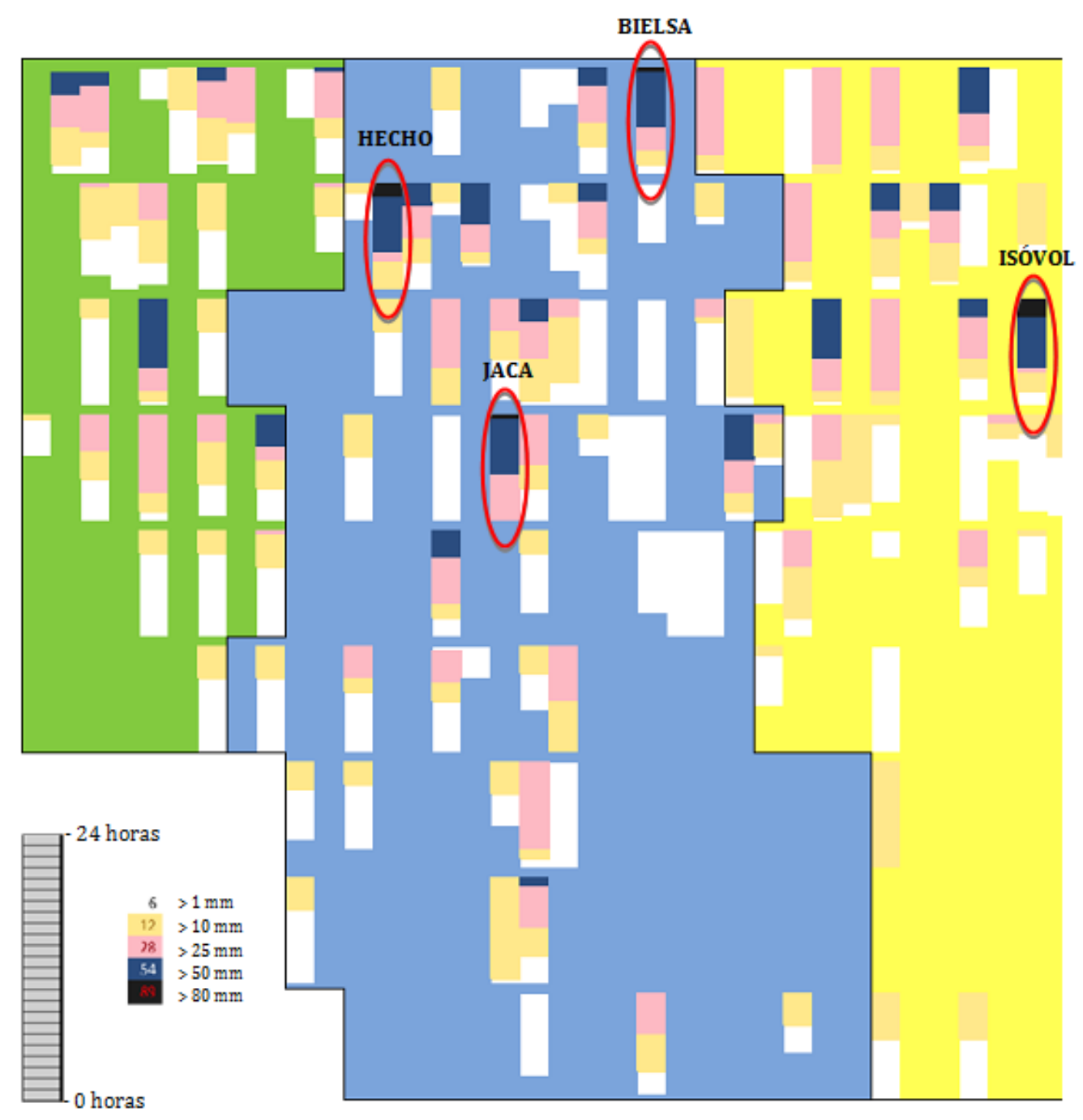

Elaboración propia.

Tabla 1. Las 20 estaciones que mayor precipitación registraron entre el 18 y 19 de junio.

\begin{tabular}{|c|c|c|c|c|c|}
\hline ID & Nombre & X & Y & Altitud & Precip. acumulada \\
\hline 8929 & Ref. Renclusa & 799197 & 4731771 & 2140 & 256 \\
\hline P080 & Belagua & 675759 & 4756989 & 1382 & 157.8 \\
\hline 8928 & Ref. Estos & 790522 & 4725869 & 1890 & 155 \\
\hline P015 & Hecho & 684023.4 & 4733446 & 817.5 & 123 \\
\hline P026 & El Cebollar & 736068 & 4726758 & 1930 & 108.8 \\
\hline 8925 & Ref. Angel Orus & 785431 & 4724014 & 2150 & 100 \\
\hline E031 & Irabia & 650319 & 4761009 & 830.9 & 99.6 \\
\hline A256 & Segre-Isòvol & 896514 & 4702594 & 1030.6 & 97.2 \\
\hline P108 & Espot & 837595 & 4719253 & 1959 & 88.4 \\
\hline 9207.sema & Hecho & 684122 & 4734459 & 860 & 87.8 \\
\hline 9784P.sema & Bielsa & 764425 & 4724773 & 990 & 87.6 \\
\hline 9201K.sema & Jaca & 701310 & 4716971 & 823 & 87.4 \\
\hline
\end{tabular}




\begin{tabular}{|c|c|c|c|c|c|}
\hline R015 & Hachueta & 584423.9 & 4756284 & 1327.4 & 82.6 \\
\hline EM35 & Ema-Bubal & 719694 & 4731125 & 1189 & 82.4 \\
\hline A198 & Vallfarrera-Alins & 855348 & 4720604 & 1080 & 80 \\
\hline E044 & Arguis & 712036 & 4686954 & 977.4 & 78.6 \\
\hline A061 & Javierregay & 684393 & 4716479 & 630.5 & 76.4 \\
\hline A282 & Aragón-Martes & 673812 & 4717834 & 554 & 74.8 \\
\hline P016 & Anso & 678200 & 4735602 & 900 & 74.6 \\
\hline A145 & Ésera-Eriste & 784995 & 4720101 & 830 & 74.4 \\
\hline
\end{tabular}

Fuente: AEMET, CHE.

La distribución de la precipitación acumulada (Fig. 6) muestra valores de más de 100 litros en la cabecera del Ésera, casi toda caída durante las primeras 24 horas. En el límite occidental del Pirineo aragonés también se muestran cifras de acumulación por encima de los 80 litros, especialmente en las zonas elevadas de la cabecera de los valles de Hecho y Ansó, así como en Belagua. La lluvia se extendió por toda la provincia de Huesca, disminuyendo de Norte a Sur y registrando valores desde los $72.1 \mathrm{~mm}$ de Torla, hasta los $35 \mathrm{~mm}$ de Huesca.

Figura 6. Mapa de distribución de la precipitación acumulada los días 18 y 19 de junio y estaciones de aforo más afectadas.

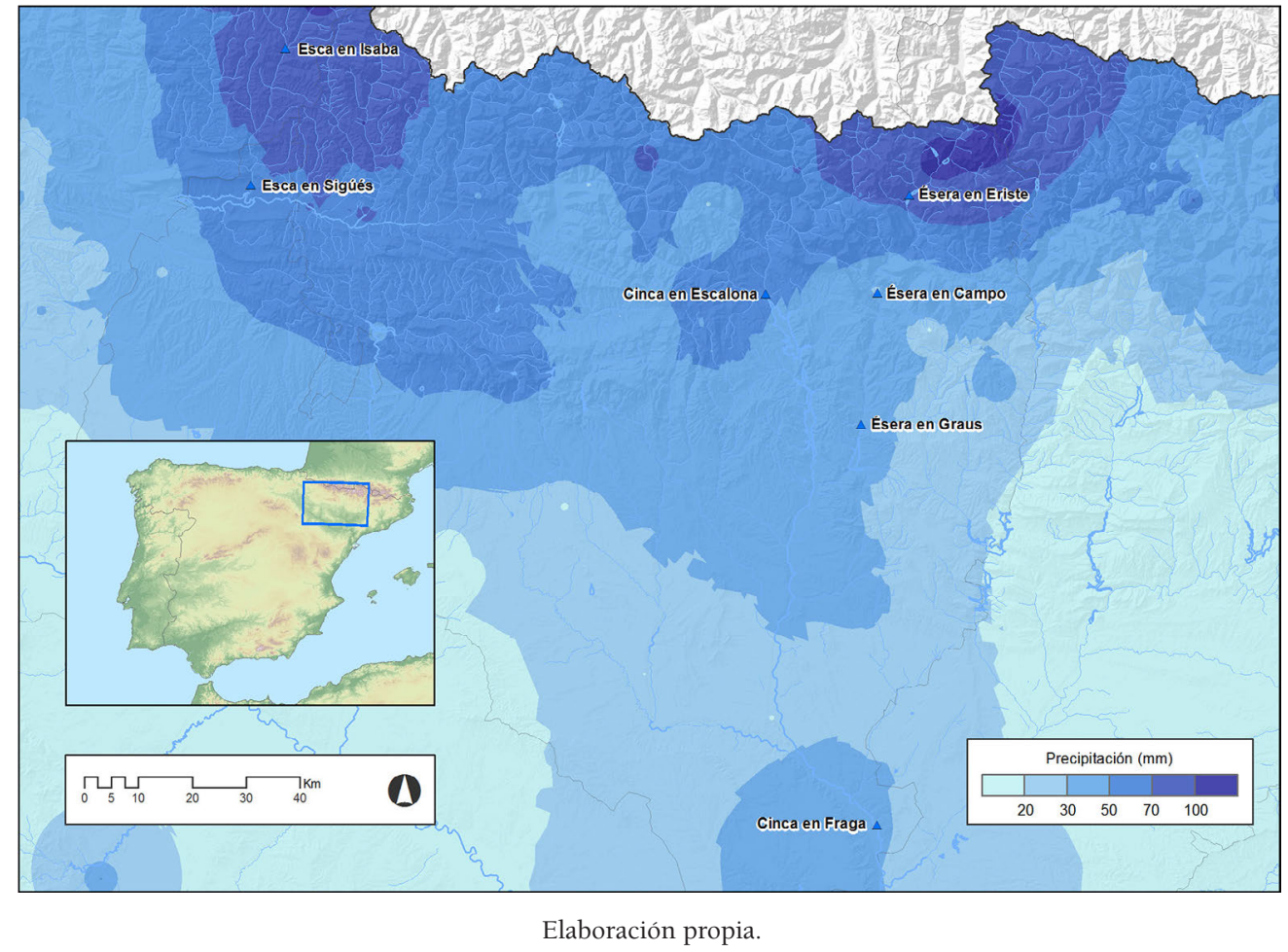

Hay que señalar que ni las intensidades, exceptuando momentos puntuales en las zonas más elevadas, ni las cantidades recogidas pueden catalogarse como excepcionales. De hecho, en el episodio del mes de octubre de 2012 (Acín et al., 2012), que ocasionó las avenidas fluviales del valle del Aragón, las precipitaciones en la parte alta del valle de Benasque fueron incluso superiores a las del actual evento, si bien en esas fechas el aporte de la fusión de nieve fue inexistente.

\section{RESPUESTA HIDROLÓGICA}

Tanto el desarrollo de la respuesta hidrológica del evento de los días 18 y 19, como la intensidad de los efectos, fueron muy similares a los sufridos en las crecidas de agosto de 1963 y noviembre de 1982.

Con la primera hubo desbordamientos importantes en Ésera, Isábena y Ribagorzana, en este último caso con $1.000 \mathrm{~m}^{3} / \mathrm{s}$ en Pont de Suert (Daumas, 1964). En Senet un alud de derrubios de un millón de 
metros cúbicos (barranc de la Runada) obturó el cauce del río Ribagorzana (Bordonau, 1992). En Bono la crecida destruyó 9 casas y la iglesia románica, en Vilaller derribó el puente románico y en Pont de Suert el puente colgante y 7 casas. También sucumbieron los puentes de Serradúy en el Isábena y de Campo en el Ésera. Muchos daños también se registraron en Arties (vall d'Aran). En el valle de Benasque se inundó Anciles. Se registró también una importante crecida en el Vero, afectando a Barbastro, donde el nivel subió 5 metros, inundándose buena parte del casco urbano. En conjunto, hubo importantes daños en todas las centrales hidroeléctricas y numerosos tramos de carretera cortados, pero no hubo víctimas mortales.

Las precipitaciones de noviembre de 1982 generaron crecidas muy notables en todos los valles pirenaicos (García Ruiz et al., 1983). En el Cinca el día 7 se registró en Escalona un caudal medio de $1.085 \mathrm{~m}^{3} / \mathrm{s}$, llegando el pico de crecida al día siguiente a Fraga, donde se midió un caudal medio diario de $2.346 \mathrm{~m}^{3} / \mathrm{s}$. La ciudad de Fraga, recién desarrollados sus barrios nuevos en el espacio inundable del Cinca, sufrió una extensa inundación, superándose los $1,8 \mathrm{~m}$ de altura del agua en algunas calles (Ollero, 2006). En Cataluña se produjeron 9 víctimas mortales y unos daños de unos 250 millones de euros (Olcina, 2006). Los efectos geomorfológicos de estas crecidas fueron analizados en Aragón por Martí y Puigdefábregas (1983) y en Cataluña por Clotet et al. (1989) y por Corominas y Alonso (1990).

Durante el evento de los días 18 y 19 de junio de 2013, la respuesta hidrológica de las diferentes cuencas pirenaicas fue proporcional a la intensidad de las precipitaciones recibidas, sumándose a ellas una importante fusión nival. Esta respuesta se manifiesta en importantes episodios de crecida en la cuenca del Esca y en la cuenca alta del Cinca, incluyendo la de su afluente el río Ésera. Hacia el Este también el río Noguera Ribagorzana incrementó de forma considerable su caudal, aunque en menor proporción que los cursos fluviales mencionados.

Los datos, tanto de nivel y caudal como de precipitaciones, registrados y recopilados en diferentes estaciones de aforo incluidas en el Sistema Automático de Información Hidrológica del Ebro (SAIH - Ebro), permiten analizar, mediante la elaboración de los correspondientes hidrogramas, la magnitud, dinamismo y evolución de las crecidas en las mencionadas cuencas.

Los correspondientes a la cuenca del Cinca, incluido el río Ésera, evidencian que la mayor magnitud de la crecida queda restringida a su cabecera. Se aprecia que la diferencia entre los valores del pico de crecida en Escalona y Fraga es muy reducida, inferior a $100 \mathrm{~m}^{3} / \mathrm{s}$, dato impensable si toda la cuenca hubiera sido afectada por precipitaciones intensas; además, se observa que sólo el río Ara, al margen del Ésera, efectuó una aportación de cierto calado a su río principal, el Cinca, en tanto que los caudales no se incrementaron significativamente en ríos como Flumen, Vero ó Alcanadre.

Respecto a la evolución de la crecida en el propio Cinca (Fig. 7), se aprecia cierto incremento de caudal, previo al evento de crecida analizado, entre los días 14 y 16 de junio, asociado a las precipitaciones

Figura 7. Hidrograma de crecida del río Cinca.

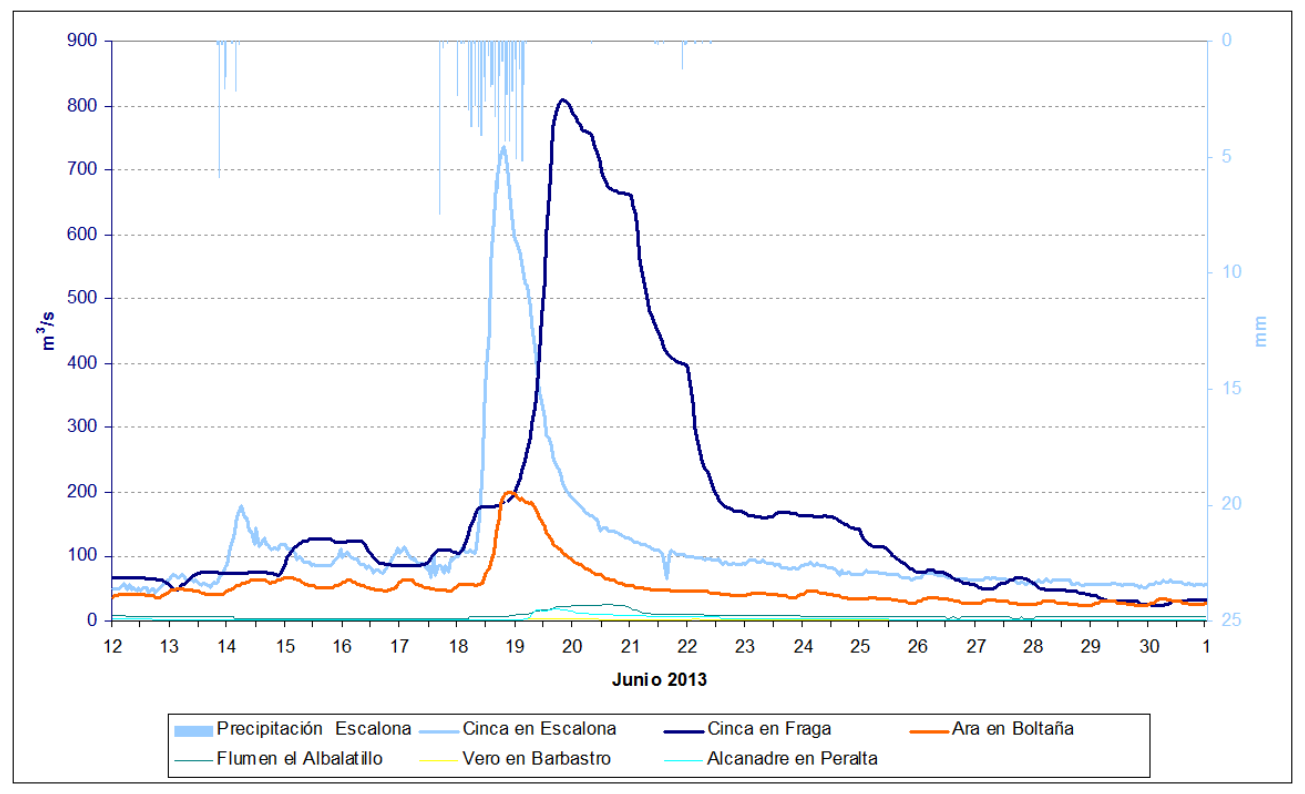

Fuente: CHE y elaboración propia. 
del día 14. El incremento brusco del caudal del Cinca se produce durante el día 18 en Escalona, de forma muy rápida, alcanzándose un pico de crecida de $738 \mathrm{~m}^{3} / \mathrm{s}$ a las $19 \mathrm{~h}$. Por su parte, la curva que refleja la evolución del caudal en la estación de aforo de Fraga empieza a dibujar un ascenso el mismo día 18 , si bien se desarrolla básicamente durante el día 19 en el que se obtiene un pico de $810,72 \mathrm{~m} 3 / \mathrm{s}$. La curva de descenso es muy pronunciada en Escalona, donde casi se ha completado al finalizar el día 19 y más escalonada en Fraga, en buena medida debido a la gestión de los embalses de la cuenca durante el episodio de crecida, aunque también el caudal desciende rápido los días 20 y 21 de junio.

La magnitud de la crecida parece destacable en Escalona, ya que la cresta de la crecida multiplica en torno a 25 veces el módulo anual, aunque faltan datos históricos de máximas instantáneas que nos permitan ratificar hasta que punto. Por su parte, el pico de crecida alcanzado en Fraga queda muy por debajo de valores históricos, entre los que sobresalen los $2201 \mathrm{~m}^{3} / \mathrm{s}$ de octubre de 1965, los 2269,3 m³ $/ \mathrm{s}$ de enero de 1977 ó los 2442,5 m³/s de octubre de 1977; por encima de todos destacan los 4194,82 m³/s apuntados para noviembre de 1982, aunque el dato sigue pendiente de verificación. En la reducción de proporciones de la crecida en Fraga tiene mucho que ver el carácter muy concentrado en cabecera de las lluvias intensas, así como la retención de agua efectuada en los distintos embalses de la cuenca, especialmente en Mediano cuyo volumen de agua embalsada se incrementó en $21,8 \mathrm{Hm}^{3}$ entre las 00 horas del día 18 y las $12 \mathrm{~h}$. del día 19. En este lapso temporal el embalse retuvo de media más de $160 \mathrm{~m}^{3} / \mathrm{s}$ de caudal, superando la retención los $220 \mathrm{~m}^{3} / \mathrm{s}$ desde el día 18 a mediodía hasta las 06 h. del día 19.

Aunque también en la subcuenca del río Ésera las lluvias caídas durante el día 14 de junio habían producido cierta elevación del caudal circulante, son las que se inician hacia las $18 \mathrm{~h}$. del día 17 las que originan el importante episodio de crecida (Fig. 8). Así, desde las primeras horas del día 18 el caudal circulante por el río Ésera aumenta con enorme rapidez, registrándose el pico de crecida en la tarde de esa misma jornada. Dicho pico se constata en las tres estaciones de aforo ubicadas en este río, Eriste $(304,9$ $\left.\mathrm{m}^{3} / \mathrm{s}\right)$, Campo $\left(460,7 \mathrm{~m}^{3} / \mathrm{s}\right)$ y Graus $\left(464,57 \mathrm{~m}^{3} / \mathrm{s}\right)$, tardando dos horas en llegar de un aforo al siguiente. En lo que restaba del día 18 y el día 19 se completó la curva de descenso, dejando paso a una más prolongada curva de agotamiento. Precisamente, una de las características destacadas de la crecida fue su brevedad y rapidez de avance: podemos decir que está activa mientras dura el episodio de precipitaciones de los días 18 y 19 de junio.

Figura 8. Hidrograma de crecida del río Ésera.

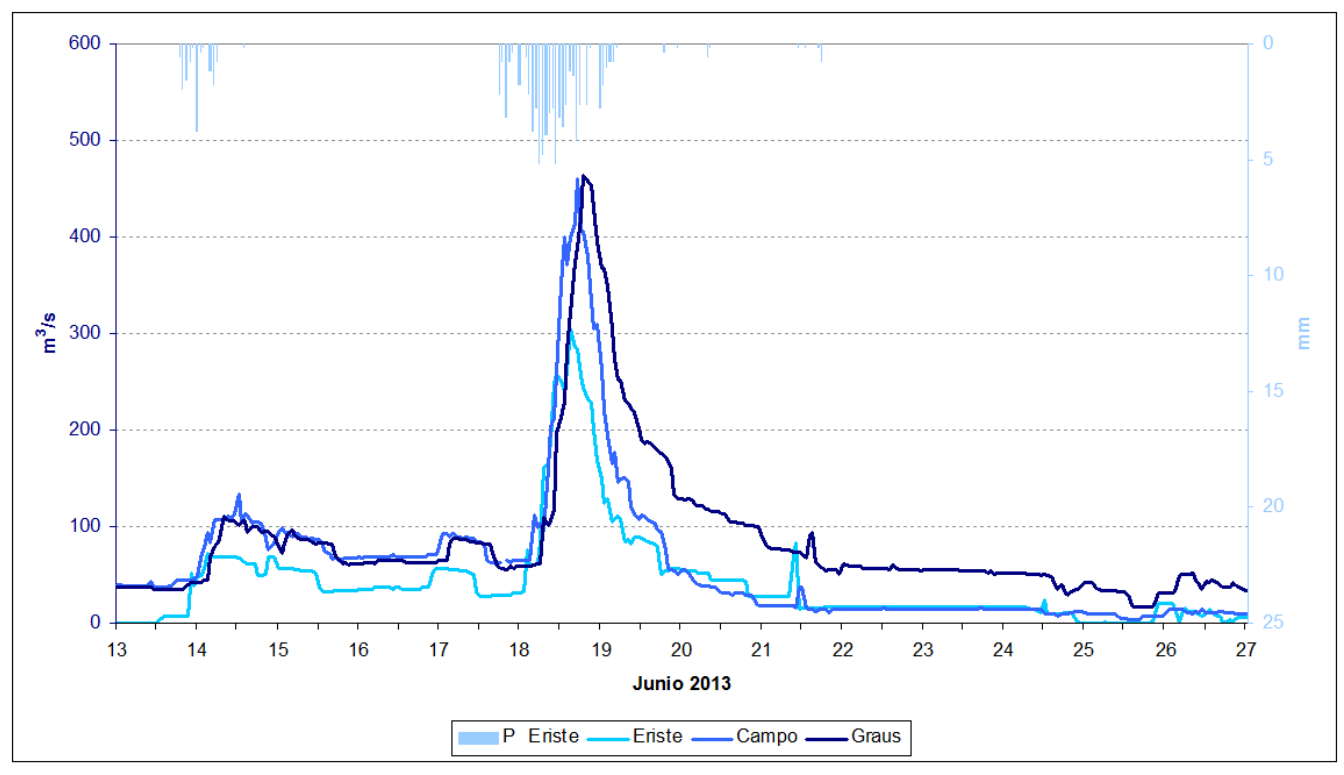

Fuente: CHE y elaboración propia.

Los registros históricos existentes sólo baten en una ocasión los alcanzados en Eriste $\left(600 \mathrm{~m}^{3} / \mathrm{s}\right.$ en agosto de 1963) y en Campo (772,52 $\mathrm{m}^{3} / \mathrm{s}$ en noviembre de 1977). Sin embargo, en Graus, donde la serie es continua desde 1949/1950, el valor del pico de esta crecida queda por debajo de los obtenidos en 7 ocasiones $\left(995 \mathrm{~m}^{3} / \mathrm{s}\right.$ en agosto de 1963, $720 \mathrm{~m} 3 / \mathrm{s}$ en octubre de 1963...). También esto, aunque con la 
limitación de que las series de las tres estaciones de aforo no abarcan periodos similares, parece ser reflejo de la concentración de las lluvias en el tramo de cabecera del Ésera.

Por su parte, el río Esca incrementó su caudal de forma considerable pero esencialmente muy rápida tras las lluvias caídas puntualmente en la tarde del día 17 de junio y, con mayor continuidad, desde el inicio del día 18. La curva de ascenso se completó en poco más de media jornada, alcanzándose un pico principal de $99,8 \mathrm{~m} 3 / \mathrm{s}$ en Isaba y 186,95 m3/s en Sigües durante el mediodía del mismo día 18, con tan sólo una hora de diferencia. Tras un momentáneo descenso del caudal, se registró un pico secundario, aunque de muy parecido rango $\left(90,5 \mathrm{~m}^{3} / \mathrm{s}\right.$ en Isaba y $185,9 \mathrm{~m}^{3} / \mathrm{s}$ en Sigües), apenas iniciada la jornada del 19 de junio. Durante el resto del día 19 los caudales descendieron rápidamente, ralentizándose el proceso a partir del día siguiente (Fig. 9).

Figura 9. Hidrograma de crecida del río Esca.

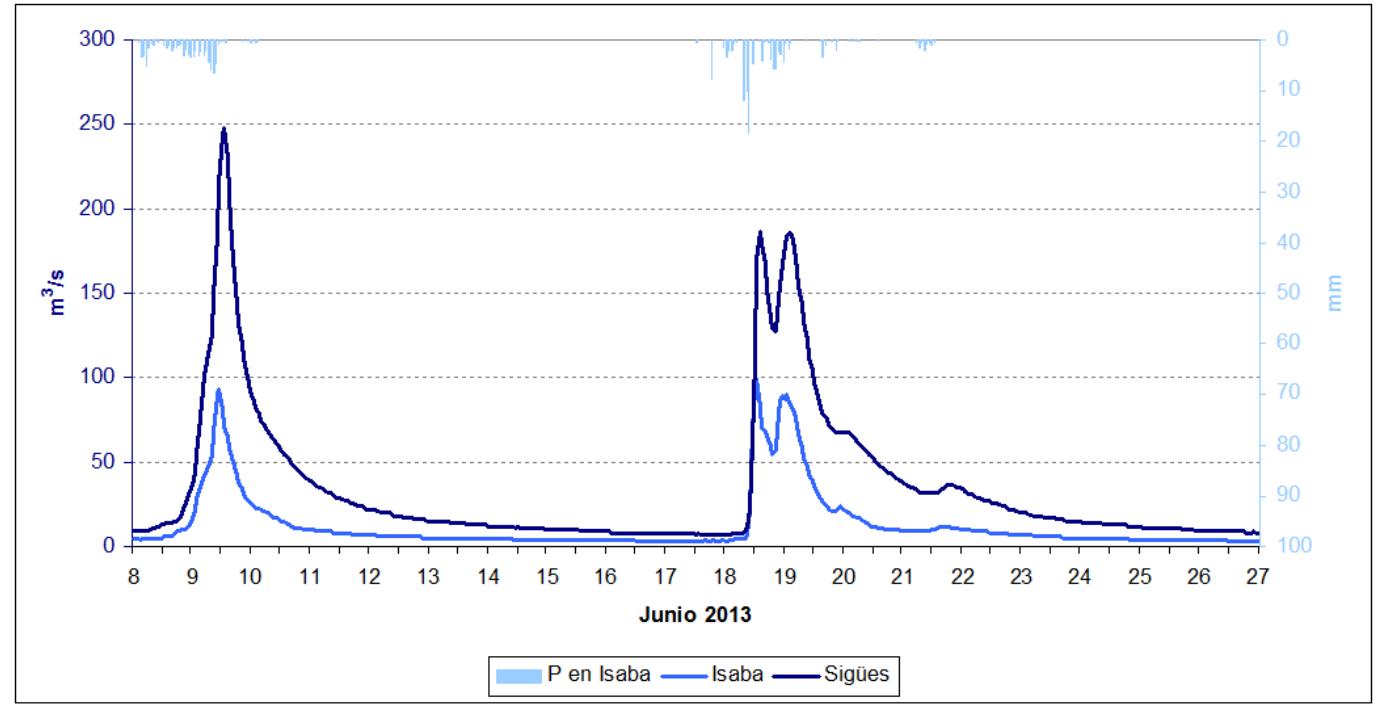

Fuente: CHE y elaboración propia.

Esta fulgurante respuesta de los caudales ante las precipitaciones estuvo, sin duda, motivada por hallarse húmedos la vegetación y los suelos de la cuenca, debido a las lluvias caídas durante los días 8 y 9 de junio. Estas habían propiciado otro episodio de crecida del río Esca, de evolución muy rápida entre los días 8 y 10, con un pico sensiblemente superior a los ya consignados en el caso de Sigües $(247,95$ m $3 / \mathrm{s})$, alcanzado a las 13 h. del día 9 de junio.

En Isaba la serie de datos es corta, pero en Sigües los valores máximos alcanzados en las dos crecidas recogidas en el hidrograma quedan muy lejos tanto de los $400 \mathrm{~m}^{3} / \mathrm{s}$ superados en 1956 y 1984, como de los 500 ampliamente rebasados en 1937 y 1956.

\section{DISCUSIÓN}

A pesar de las importantes precipitaciones registradas por muchos de los observatorios del macizo pirenaico, este evento no fue de los mayores registrados históricamente, ni siquiera en el año hidrológico 2012-13 en curso, ya que en octubre de 2012 se registraron acumulados e intensidades superiores en muchas de las estaciones del Pirineo aragonés. En aquel evento otoñal la respuesta hidrológica fue mucho más significativa en las cuencas occidentales de Aragón y Gállego. Incluso en la cuenca del Cinca los cursos más afectados fueron el Ara y el Alcanadre y afluentes (Acín et al., 2012), mientras el Ésera no pasó de una crecida ordinaria. Sin embargo, en el evento de junio de 2013 la entrada en escena de una importante parte de fusión nival, debida, por otro lado, a la abundante innivación del invierno y primavera previos y a la escasa acumulación de altas temperaturas en el primer semestre del año, produjo un incremento del caudal que consolidó una crecida de gran magnitud, principalmente en el río Ésera, que superó la capacidad del cauce menor en muchas localizaciones concretas, entre otras la población de Benasque y urbanizaciones aledañas. 
La recurrencia de dos eventos de notable intensidad, a escala de todo el Pirineo aragonés, dentro del mismo año hidrológico actual (2012-2013) reabre la pregunta de si es posible y útil determinar la periodicidad de ocurrencia de estos fenómenos. La experiencia y la bibliografía marcan que solo en zonas con precipitaciones muy regulares y con amplios registros históricos (no es el caso de nuestro área de estudio), la estimación de periodos de retorno son relativamente fiables (Beguería y Lorente, 1999).

La cadena de consecuencias de un evento de precipitación mayor de lo habitual comienza con la precipitación, los procesos de vertiente, una acumulación de caudal en los cauces, unos procesos hidrogeomorfológicos en los mismos y en las áreas inundables y unos daños sobre el medio humano.

Los mayores efectos del evento se dieron especialmente el 18 de junio en el valle de Benasque (Tabla 2), donde las modificaciones en el cauce menor del Ésera se hicieron notables desde la cabecera, en los Llanos del Hospital, hasta el embalse de Linsoles pasando por la propia población de Benasque. Allí se produjeron importantes daños sobre las carreteras, sobre construcciones limítrofes con el cauce del río y sobre las propias defensas instaladas en los márgenes del cauce. Los daños en el valle de Arán fueron también muy destacables, con carreteras cortadas e interrupción del suministro de agua potable. En Francia las crecidas del 18 de junio también provocaron graves daños en infraestructuras y vías de comunicación, especialmente en Bigorre (Barèges y Lourdes), con dos víctimas mortales.

Tabla 2. Principales consecuencias y afecciones producidas por el evento hidrológico de junio de 2013 en el valle de Benasque.

\begin{tabular}{|c|c|}
\hline \multicolumn{2}{|r|}{ Consecuencias en el medio natural } \\
\hline \multirow{3}{*}{ Llanos del Hospital } & erosión en márgenes \\
\hline & sedimentación en amplias zonas del llano y zona del vado \\
\hline & incisión \\
\hline \multirow{3}{*}{ Llano de Turpí } & erosión en márgenes \\
\hline & sedimentación en amplias zonas del llano y zona del vado \\
\hline & incisión \\
\hline \multirow{2}{*}{ Tramo Turpí-Senarta } & erosión en márgenes \\
\hline & movimiento del cauce menor \\
\hline \multirow{2}{*}{ Llano de Senarta } & desbordamiento con aportes de material \\
\hline & sedimentación en la cola del embalse de Paso Nuevo \\
\hline \multirow{2}{*}{ Paso Nuevo-Central de Ruda } & erosión de márgenes \\
\hline & incisión \\
\hline \multirow{4}{*}{ Central de Ruda-Benasque } & erosión de márgenes \\
\hline & zonas de sedimentación \\
\hline & movilidad del lecho menor \\
\hline & trazado de nuevos cauces menores \\
\hline \multirow{2}{*}{ Benasque } & erosión en márgenes y ampliación de curvas \\
\hline & incisión \\
\hline \multirow{3}{*}{ Benasque-Linsoles } & cambios en trazado del cauce \\
\hline & erosión de márgenes \\
\hline & deposición de sedimentos en zona baja \\
\hline \multirow{3}{*}{ Zona baja } & movilidad del cauce menor \\
\hline & erosión de márgenes, ampliación de curvas \\
\hline & puntuales sedimentaciones \\
\hline \multicolumn{2}{|r|}{ Afecciones a infraestructuras } \\
\hline Llanos del Hospital & afecciones a puente del vado, puente del llano y senderos \\
\hline Llano de Turpí & afecciones puntuales en puentes \\
\hline Tramo Turpí-Senarta & afecciones en pista forestal, tramos desaparecidos \\
\hline \multirow{2}{*}{ Llano de Senarta } & puente de acceso sepultado \\
\hline & pista dañada \\
\hline
\end{tabular}




\begin{tabular}{|c|c|}
\hline \multirow{3}{*}{ Paso Nuevo-Central de Ruda } & puente camping Aneto dañado \\
\hline & puente Ruda sepultado \\
\hline & escolleras arrastradas \\
\hline \multirow{5}{*}{ Central de Ruda-Benasque } & escolleras y gaviones arrastrados \\
\hline & traída de aguas de Benasque destruida \\
\hline & carretera A-136 destruida en varios puntos \\
\hline & zona de picnic destruida \\
\hline & senderos destruidos \\
\hline \multirow{6}{*}{ Benasque } & camino de huertos destrozado \\
\hline & escolleras arrastradas \\
\hline & partes del muro arrastradas \\
\hline & socavamiento de puentes y defensas \\
\hline & toma de agua alcantarillado destrozada \\
\hline & puente "la palanca" destrozado \\
\hline \multirow{7}{*}{ Benasque-Linsoles } & camino ribereño destruido \\
\hline & muros parcialmente destruidos \\
\hline & escolleras destrozadas \\
\hline & puente de Linsoles Alto inutilizado \\
\hline & puente de Linsoles muy dañado \\
\hline & puente Eriste casi cegado \\
\hline & carretera inundada \\
\hline \multirow{4}{*}{ Zona baja } & afecciones puntuales en carretera (Arnaldet, Castejón, El Run, Ventamillo, Seira...) \\
\hline & destrucción de escolleras y motas \\
\hline & afecciones a gaviones en Villanova \\
\hline & afecciones a pistas forestales cercanas al cauce \\
\hline \multicolumn{2}{|r|}{ Afecciones urbanísticas } \\
\hline Llano de Senarta & afecciones a caseta de recepción \\
\hline Paso Nuevo-Central de Ruda & potabilizadora inutilizada \\
\hline Central de Ruda-Benasque & afecciones al acceso al polígono industrial \\
\hline \multirow{4}{*}{ Benasque } & algunos edificios expuestos directamente al agua \\
\hline & caseta de Cazadores destrozada \\
\hline & afecciones a instalaciones de depuración de aguas residuales \\
\hline & inundacones en calle Mayor \\
\hline \multirow{4}{*}{ Benasque-Linsoles } & edificios expuestos directamente al flujo en La Granja y Linsoles \\
\hline & pistas polideportivas de Peguera anegadas y dañadas \\
\hline & urbanización Linsoles inundada \\
\hline & edificios de Eriste inundados \\
\hline \multirow{3}{*}{ Zona baja } & zonas deportivas anegadas en Villanova y Castejón \\
\hline & camping de Castejón de Sos destrozado \\
\hline & afecciones en depuradora de Castejón de Sos \\
\hline
\end{tabular}

Elaboración propia.

Por tanto, las consecuencias de este evento han sido positivas en cuanto a la reactivación de procesos geomorfológicos fluviales, pero los daños en el medio humano han sido importantes, tanto en vías de comunicación como en usos urbanos. Este hecho pone de manifiesto un problema desarrollado e incrementado progresivamente a lo largo de las últimas décadas: la ocupación del espacio del río o territorio fluvial con usos no compatibles con la inundación y con los procesos naturales de erosión y cambio de trazado de los cauces. Las siguientes figuras muestran imágenes aéreas comparativas de 1956 y de 2009 del cauce del Ésera en Benasque (Fig. 10), Linsoles (Fig. 11) y Castejón de Sos (Fig. 12). En todas ellas es evidente la ocupación no solo de la llanura de inundación, sino incluso del propio cauce trenzado de mediados del siglo XX. 
Figura 10. Comparativa 1956-2009 en Benasque. El núcleo urbano de Benasque ha sufrido un importante crecimiento en las últimas décadas. Como consecuencia de ello se han desarrollado edificaciones muy cercanas al cauce que en el pasado evento se vieron afectadas debido al desmoronamiento de algunas defensas sobre las que, prácticamente, se asentaban. Junto a estas zonas residenciales han proliferado otras edificaciones y espacios de equipamientos dentro de zonas inundables, lo que ha conllevado elevados daños en los mismos pese a la presencia de costosos sistemas de defensa.
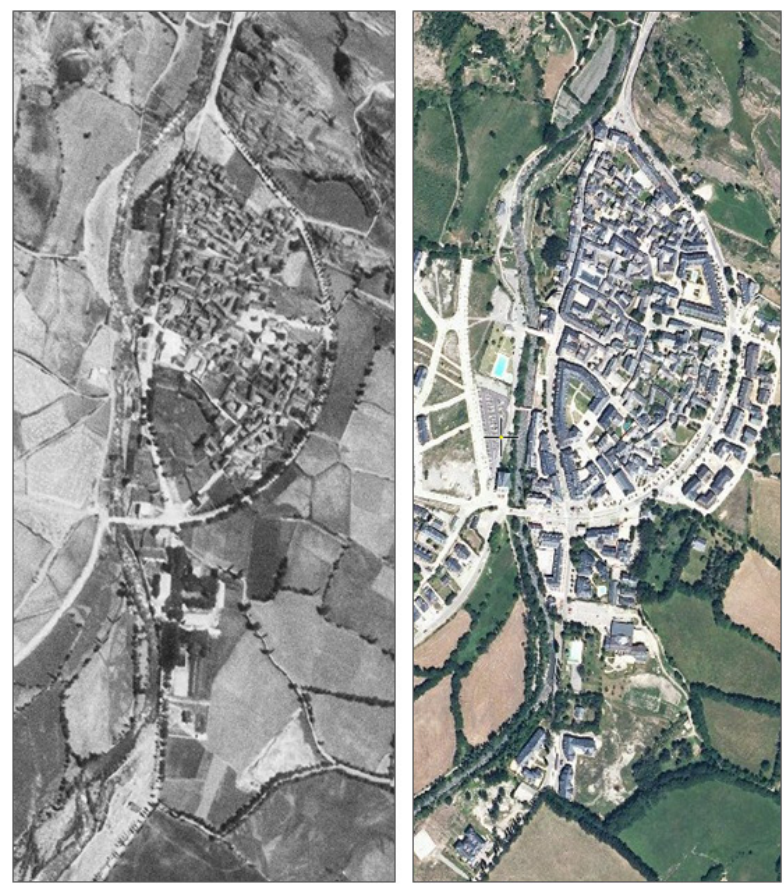

Fuente: Sistema de Información Territorial de Aragón (SITAR).

Figura 11. Comparativa 1956-2009 en la urbanización Linsoles. Ejemplo claro del proceso urbanizador, se ha desarrollado una importante zona residencial ocupando parte del cauce mayor del río. Además, esta urbanización se encuentra en el flanco sur del importante cono de deyección del Remáscaro. La zona sufrió inundaciones en la crecida, además de quedar edificios directamente expuestos a la corriente. La comparativa muestra cómo desde 1956 la regulación de caudales y las presiones por usos antrópicos han conllevado la simplificación del cauce y la reducción de su espacio.

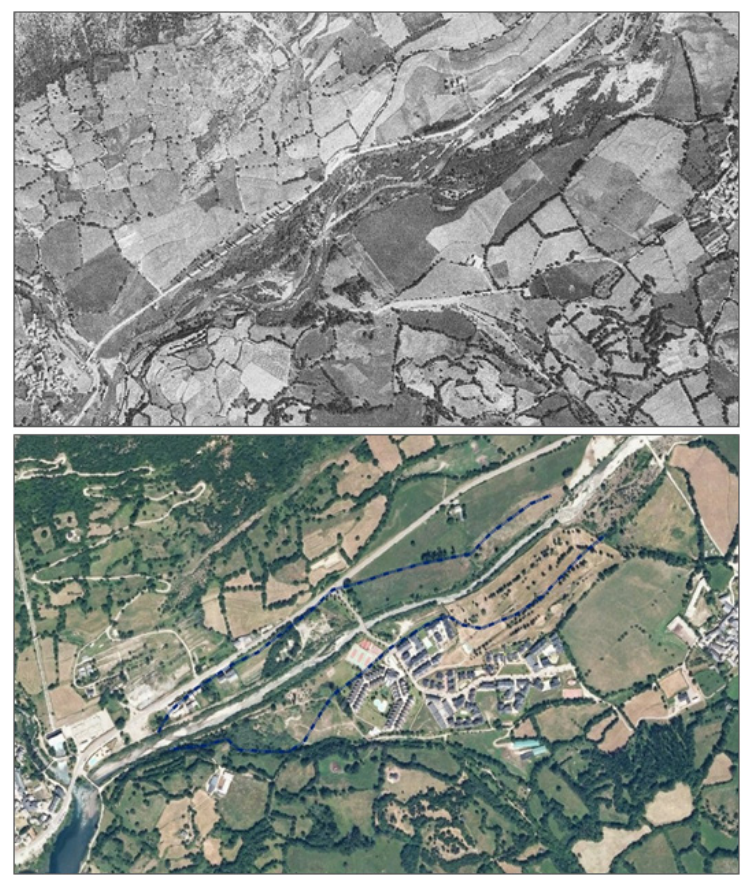

Fuente: SITAR. 
Figura 12. Comparativa 1956-2009 en Castejón de Sos. Poco antes de que el río Ésera se confine en el Congosto de Ventamillo éste circula dejando en su margen derecha la zona de camping y equipamientos deportivos de Castejón de Sos. Esta zona, como se aprecia en las fotos, se asienta sobre el antiguo cauce del Ésera, de nuevo reduciendo su espacio de movilidad y, como se ha demostrado, pese a los importantes y costosos sistemas de motas y escolleras que se crearon entre la zona de acampada y el río, suponiendo un evidente riesgo para los usuarios de esos equipamientos.
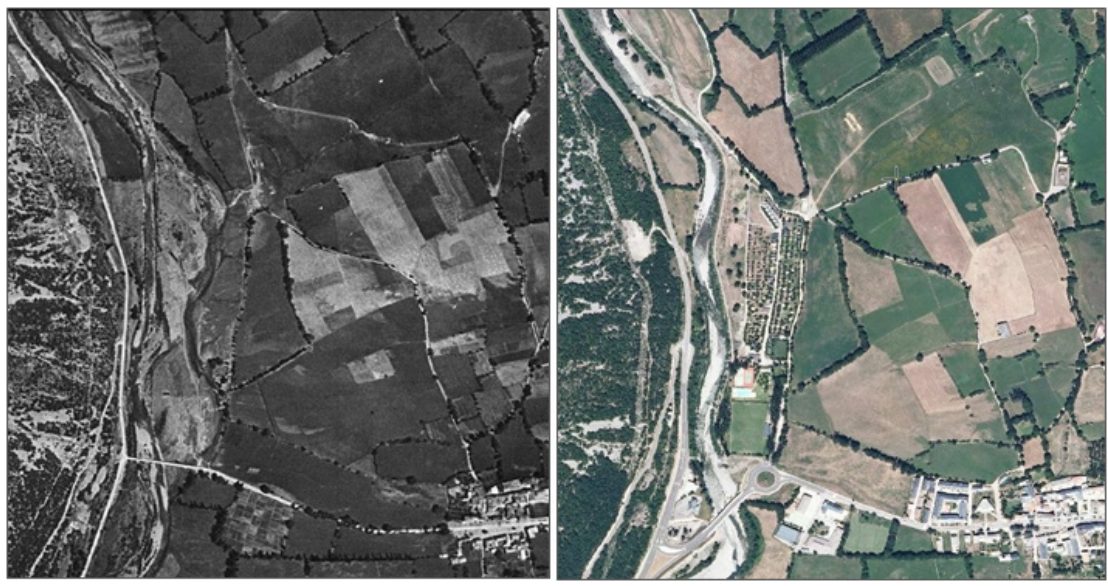

Fuente: SITAR.

Ante esta situación, era previsible y hay que calificar de esperable que el río Ésera volviera a ocupar su cauce en una crecida extraordinaria como la acontecida en junio de 2013, e incluso que iniciara procesos erosivos intensos en las márgenes. Muchas defensas existentes, la mayoría de ellas adosadas de forma directa al cauce menor, han sido destruidas o superadas con facilidad, demostrando su nula utilidad frente a eventos de alta intensidad hidrológica.

Figura 13. Comparativa de las actuaciones llevadas a cabo 4 meses después del evento (arriba) y la situación natural inmediatamente posterior a la crecida. Aguas abajo de Benasque.
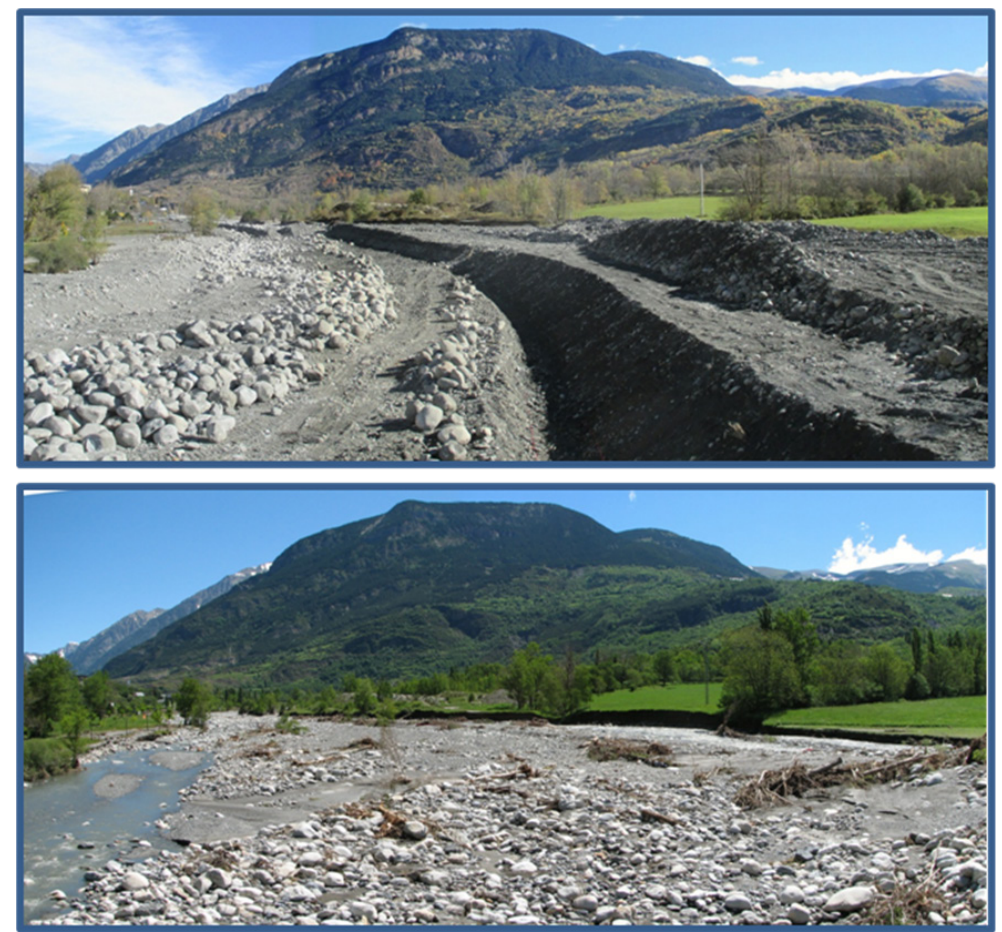

Foto: Daniel Mora.

Otro aspecto interesante en el debate científico-técnico es el tratamiento post-crecida. Desde ámbitos científicos y ambientalistas (Colegio de Geógrafos y Centro Ibérico de Restauración Fluvial, por ejemplo) 
se ha abogado por respetar el trabajo del río durante la avenida, un trabajo de redimensionamiento y autorregulación del cauce para la correcta evacuación de la crecida, considerando que habría que adaptar los usos humanos ante las nuevas condiciones hidrogeomorfológicas. Sin embargo, desde el Ministerio de Agricultura, Alimentación y Medio Ambiente, a través de la Confederación Hidrográfica del Ebro, se han ejecutado rápidas obras de emergencia tratando de reconducir el cauce del río Ésera dentro de una sucesión de encauzamientos realizados sin proyecto y sin control ambiental. Para ello se han invertido 4 millones de euros, a sumar a los ejecutados por la demarcación de carreteras, que igualmente ha realizado obras en el cauce para estabilizar márgenes y realizar nuevas rotondas, o por el Instituto Aragonés del Agua, relacionadas con las conducciones que componen la traída de aguas a Benasque. Desde el ámbito científico y ambiental han sido muy criticadas estas medidas, que están suponiendo un deterioro sin precedentes del cauce, declarado Lugar de Importancia Comunitaria, destruyendo totalmente la naturalidad fluvial, las morfologías de lecho y márgenes y los depósitos sedimentarios recuperados con el evento de crecida (Fig. 13). Con estas actuaciones, contrarias a los principios de las directivas europeas del Agua (2000/60/CE), de Inundaciones (2007/60/CE) y de Impacto Ambiental (2011/92/CE), es muy cuestionable que se reduzca la peligrosidad, mientras se incrementa la falsa sensación de seguridad en la población y se pueden fomentar nuevas actuaciones urbanísticas en áreas de alto riesgo.

Estas formas de actuación post-crecida y el debate correspondiente ya tuvieron lugar en términos similares tras los eventos de octubre de 2012 (Acín et al., 2012) y en otros casos anteriores. La repercusión social y en los medios de comunicación de estos problemas de gestión de situaciones de riesgo es importante, pero existe un vacío científico al respecto, aunque existen aportaciones recientes desde la Geografía (Olcina, 2008, 2009; Gonzalo et al., 2010; Sánchez Fabre y Ollero, 2010; Vinet, 2010).

\section{CONCLUSIONES}

El estudio de la situación sinóptica, así como de las intensidades de precipitación recibidas en los observatorios meteorológicos, y de los caudales de los ríos afectados, muestran que el evento de precipitación producido entre los días 18 y 19 de junio de 2013 y sus consecuencias hidrológicas, no fueron de carácter extremo en comparación a otros eventos históricos de similares características. Sin embargo, la configuración actual del territorio provocó mayores afecciones especialmente sobre el Valle de Benasque.

Las claves de la importancia del evento y su incidencia sobre el medio natural y humano pueden resumirse en las siguientes:

- Se forma una Depresión Aislada en Niveles Altos (DANA) en la zona centro-oeste de la península que, junto a vientos de levante cargados de humedad, favorece la formación de sistemas convectivos de gran intensidad.

- Las precipitaciones registradas superan los $1501 / \mathrm{m}^{2}$ en las cabeceras del Ésera y el Esca especialmente, cuyas rápidas respuestas hidrológicas se incrementan debido al aporte extra de la fusión nival. La cuenca del Cinca también experimenta un gran incremento aunque más lento que las demás.

- Las crecidas sólo alcanzan una magnitud destacada en los tramos altos de las cuencas (cabecera del Cinca, cuenca del Ésera, cabecera del Esca), donde las precipitaciones fueron más intensas.

- Las consecuencias de las avenidas han reactivado procesos geomorfológicos fluviales, reocupando antiguos llanos de inundación, aunque la intensa ocupación territorial de los últimos 50 años en el Valle de Benasque ha producido que la exposición al riesgo sea mucho mayor como consecuencia del escasamente controlado y desordenado crecimiento urbanístico.

- Se trata de una crecida hidrológica cuyas consecuencias habrían podido ser evitadas, ya que la intensidad del evento no era impredecible, los indicios geomorfológicos del entorno eran claros, y la exposición al riesgo excesivamente alto.

\section{RECURSOS ELECTRÓNICOS}

ACÍN, V., BALlaríN, D., BRUFAO, P, DOMENECH, S., ESPEJO, F., GONZÁlEZ-HIDALGO, J.C., GRANADO, D., IBISATE, A., MARCÉN, C., MORA, D., NADAL, E., OLLERO, A., SÁNCHEZ FABRE, M., SAZ, M.A., SERRANO-NOTIVOLI, R. (2012): "Sobre las precipitaciones de octubre de 2012 en el Pirineo aragonés, su respuesta hidrológica y la gestión de riesgos", en Geographicalia, no 61, pp. 101-108. 
Álvarez, E., ESPEJO, F., CORTÉS, FJ., LAFRAGÜETA, C., SERRANO-NOTIVOli, R. (2011): Caracterización sinóptica de los procesos convectivos en el interior del Nordeste peninsular. Agencia Estatal de Meteorología. NIPO: 784-11-008-8.

ANTOINE, J.M., DESAILLY, B., GAZELLE, F. (2001): "Les crues meurtrières, du Roussillon aux Cévennes", en Annales de Géographie, n 662, pp. 597-623.

BEGUERÍA, S., LORENTE, A. (1999): "Distribución espacial del riesgo de precipitaciones extremas en el Pirineo aragonés occidental", en Geographicalia, n 37, pp. 17-36.

BORDONAU, J. (1992): Els complexos glàcio-lacustres relacionats amb el darrer cicle glacial als Pirineus. Geoforma Ediciones, 251 p., Logroño.

CADiÑANOS, J.A., GONZÁLEZ AMUCHASTEGUI, M.J., MEAZA, G., OLLERO, A., ORMAETXEA, O. (2001): "Medios dinámicos en la cabecera del río Ésera (Pirineo Central)", en Treballs de la Societat Catalana de Geografia, no 52, pp. 137-163.

CLOTET, N., GARCÍA RUIZ, J.M., GALLART, F. (1989): "High magnitude geomorphic work in Pyrenees range: unusual rainfall event, november 1982", en Studia Geomorphologica Carpatho-Balcanica, n ${ }^{\circ}$ XXIII, pp. 69-91.

COROMINAS, J., ALONSO, E.E. (1990): "Geomorphological effects of extreme floods (November 1982) in the southern Pyrenees", en Hydrology in mountainous regions. II. Artificial reservoirs: water and slopes. Proceedings of two Lausanne Symposia. IAHS Publ. 194, pp. 295-302.

CUADRAT, J.M., SERRANO-NOTIVOLI, R., SAZ, M.A., MARÍN, J.M. (2012): "Patrones temporales y espaciales de la precipitación en Aragón desde 1950". Geographicalia, n 59, pp. 85-94.

Daumas, M. (1964): Les crues du 3 Août 1963 dans les hautes vallées aragónaises et catalanes. Revue Géographique des Pyrénées et du Sud-Ouest, 35: 305-310.

DEL VAlle, J.; OlleRO, A., SÁNCHEZ FABRE, M. (2007): Atlas de los ríos de Aragón. Prames, 479 p., Zaragoza.

GARCÍA RUIZ, J.M., PUIGDEFÁBREGAS, J., MARTÍN-RANZ, M.C. (1983): "Diferencias espaciales en la respuesta hidrológica a las precipitaciones torrenciales de noviembre de 1982 en el Pirineo Central", en Estudios Geográficos, n 170-171, pp. 291-316.

GARCÍA RUIZ, J.M., ARNÁEZ, J., WHITE, S., BORDONABA, A.P. (1998): "Predicción de eventos extremos en áreas de montaña. El ejemplo del Pirineo Central", en GÓMEZ ORTIZ, A., SALVADOR, F. (Eds.): Investigaciones recientes de la Geomorfología española, pp. 623-630, Sociedad Española de Geomorfología, Barcelona.

GARCÍA-RUIZ, J.M., BEGUERÍA, S., LORENTE, A. (2000a): "Eventos hidrológicos de baja frecuencia en el Pirineo central español y sus efectos geomorfológicos", en Serie Geográfica, no 9, pp. 163-176.

GARCÍA-RUIZ, J.M., ARNÁEZ, J., WHITE, S.M., LORENTE, A., BEGUERÍA, S. (2000b): "Uncertainty assessment in the prediction of extreme rainfall events: an example from the central Spanish Pyrenees", en Hydrological Processes, $n^{\circ}$ 14, pp. 887-898.

GONZÁlEZ AMUCHASTEGUI, M.J., MEAZA, G., OllERO, A., ORMAETXEA, O. (1998): "Caracterización de la dinámica del Ésera alto y medio (Pirineo Aragonés). Primeros resultados", en GÓMEZ ORTIZ, A., SALVADOR, F. (Eds.): Investigaciones recientes de la Geomorfología española, pp. 193-202, Sociedad Española de Geomorfología, Barcelona.

GONZALO, L.E.; OlleRO, A.; IBISATE, A., BALlARÍN, D. (2010): "Impacto geomorfológico de actuaciones en cauces fluviales de La Rioja”, en Zubía, no 28, pp. 7-30.

LÓPEZ-MORENO, J.I., BEGUERÍA, S., GARCÍA-RUIZ, J.M. (2006): "Trends in high flows in the central Spanish Pyrenees: response to climatic factors or to land-use change?", en Hydrological Sciences Journal, no 51:6, pp. 1039-1050

MARTí BONO, C., PUIGDEFÁBREGAS, T. (1983): "Consecuencias geomorfológicas de las lluvias de noviembre de 1982 en las cabeceras de algunos valles pirenaicos", Estudios Geográficos, n 170-171, pp. $275-289$.

OLCINA, J. (2006): "Reducción del riesgo de inundaciones en el litoral mediterráneo español. El papel de la ordenación del territorio", en CHASTAGNARET, G., GIL OLCINA, A. (Dirs.): Riesgo de inundaciones en el Mediterráneo occidental, pp. 157-214, Casa de Velázquez y Universidad de Alicante.

OLCINA, J. (2008): "Cambios en la consideración territorial, conceptual y de método de los riesgos naturales", en Scripta Nova. Revista Electrónica de Geografía y Ciencias Sociales, XII, n 270(24). http://www.ub.es/geocrit/sn/sn-270/sn-270-24.htm 
OLCINA, J. (2009): "Cambio climático y riesgos climáticos en España", en Investigaciones Geográficas, no 49 , pp. 197-220.

OLLERO, A. (2006): "Inundaciones y ordenación del territorio fluvial en la cuenca del Ebro", en CHASTAGNARET, G., GIL OlCINA, A. (Dirs.): Riesgo de inundaciones en el Mediterráneo occidental, pp. 239-272, Casa de Velázquez y Universidad de Alicante.

PLANA, J.A. (1984): "Estudio de las crecidas fluviales en el Pirineo occidental catalán, vertiente mediterránea, en el período 1935-1982", en Notes de Geografía Física, no 12, pp. 35-50.

RICO, M., BENITO, G., BARNOLAS, A. (2001): "Combined palaeoflood and rainfall-runoff assessment of mountain floods (Spanish Pyrenees)", en Journal of Hydrology, no 245, pp. 59-72.

SÁNCHEZ FABRE, M., OLLERO, A. (2010): "Agua y medio ambiente en España: diagnóstico y perspectivas de algunas líneas de acción”, en Investigaciones Geográficas, n51, pp. 53-79.

SERRANO, E., MARTÍNEZ DE PISÓN, E. (1994): "Geomorfología y evolución glaciar en el Pirineo Aragonés oriental”, en MARTÍ BONO, C., GARCÍA RUIZ, J.M. (Eds.): El glaciarismo surpirenaico: nuevas aportaciones. Geoforma, Logroño, pp. 33-64.

SERRANO-MUELA, M.P., NADAL-ROMERO, E., LANA-RENAULT, N., GONZÁLEZ-HIDALGO, J.C., LÓPEZ-MORENO, J.I., BEGUERÍA, S., SANJUÁN, Y., GARCÍA-RUIZ, J.M. (2013): "An exceptional event in the central western Pyrenees: spatial patterns in discharge and impact", en Land Degradation \& Development. Article in press.

STARON, G. (1993): "Chronologie des catastrophes pluvieuses dans le sud de la France", en Revue de Géographie de Lyon, no 68(2-3), pp. 91-100.

TRAPERO, L., BECH, J., LORENTE, J. (2013): "Numerical modelling of heavy precipitation events over Eastern Pyrenees: Analysis of orographic effects", en Atmospheric Research, nº 123, pp. 368-383.

VICENTE-SERRANO, S.M., LÓPEZ-MORENO, J.I., BEGUERÍA, S. (2007): "La precipitación en el Pirineo español: diversidad espacial en las tendencias y escenarios futuros", en Pirineos, no 162, pp. 43-69.

VINET, F. (2010): Le risque inondation. Diagnostic et gestion. Tec \& Doc Lavoisier, Paris. 